Neutron Physics 
This page intentionally left blank 


\section{Neutron Physics}

\section{Paul Reuss}

Institut national des sciences et techniques nucléaires

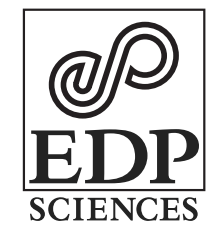

17, avenue du Hoggar

Parc d'activités de Courtabœuf, BP 112

91944 Les Ulis Cedex A, France 
The author would like to thank Nova Traduction (K. Foster) and Chris Latham for the translation of his book.

Cover illustrations: Jules Horowitz (1921-1995), a highly talented physicist, founded the French school of neutron physics. In 2014, the Jules Horowitz reactor being built at Cadarache will become the main irradiation reactor in the world $(100 \mathrm{MW}$ th) for research on materials and nuclear fuels. In the background, the meshing for a neutron physics core calculation and in the foreground the power distribution, result of this calculation. (Documents courtesy of CEA.)

Cover conception: Thierry Gourdin

Printed in France

ISBN: 978-2-7598-0041-4

This work is subject to copyright. All rights are reserved, whether the whole or part of the material is concerned, specifically the rights of translation, reprinting, re-use of illustrations, recitation, broadcasting, reproduction on microfilms or in other ways, and storage in data banks. Duplication of this publication or parts thereof is only permitted under the provisions of the French and German Copyright laws of March 11, 1957 and September 9, 1965, respectively. Violations fall under the prosecution act of the French and German Copyright Laws.

(C) EDP Sciences 2008 


\section{Introduction to the Nuclear Engineering Collection}

Within the French Atomic Energy Commission (CEA), the National Institute of Nuclear Science and Technology (INSTN) is a higher education institution operating under the joint supervision of the Ministries of Education and Industry. The purpose of the INSTN is to contribute to disseminating the CEA's expertise through specialised courses and continuing education, not only on a national scale, but across Europe and worldwide.

This mission is focused on nuclear science and technology, and one of its main features is a Nuclear Engineering diploma. Bolstered by the CEA's efforts to build partnerships with universities and engineering schools, the INSTN has developed links with other higher education institutions, leading to the organisation of more than twenty five jointly-sponsored Masters graduate diplomas. There are also courses covering disciplines in the health sector: nuclear medicine, radiopharmacy, and training for hospital physicists.

Continuous education is another important part of the INSTN's activities that relies on the expertise developed within the CEA and by its partners in industry.

The Nuclear Engineering course (known as ' $\mathrm{GA}^{\prime}$, an abbreviation of its French name) was first taught in 1954 at the CEA Saclay site, where the first experimental piles were built. It has also been taught since 1976 at Cadarache, where fast neutron reactors were developed. GA has been taught since 1958 at the School for the Military Applications of Atomic Energy (EAMEA), under the responsibility of the INSTN. Since its creation, the INSTN has awarded diplomas to over 4400 engineers who now work in major companies or public-sector bodies in the French nuclear industry: CEA, EDF (the French electricity board), AREVA, Cogema, Marine Nationale (the French navy), IRSN (French TSO). . Many foreign students from a variety of countries have also studied for this diploma.

There are two categories of student: civilian and military. Civilian students will obtain jobs in the design or operation of nuclear reactors for power plants or research establishments, or in fuel processing facilities. They can aim to become expert consultants, analysing nuclear risks or assessing environmental impact. The EAMEA provides education for certain officers assigned to French nuclear submarines or the aircraft carrier.

The teaching faculty comprises CEA research scientists, experts from the Nuclear Safety and Radiation Protection Institute (IRSN), and engineers working in industry (EDF, AREVA, etc.). The main subjects are: nuclear physics and neutron physics, thermal hydraulics, nuclear materials, mechanics, radiological protection, nuclear instrumentation, operation and safety of Pressurised Water Reactors (PWR), nuclear reactor systems, and the nuclear fuel cycle. These courses are taught over a six-month period, followed by a final project that rounds out the student's training by applying it to an actual industrial situation. 
These projects take place in the CEA's research centres, companies in the nuclear industry (EDF, AREVA, etc.), and even abroad (USA, Canada, United Kingdom, etc.). A key feature of this programme is the emphasis on practical work carried out using the INSTN facilities (ISIS training reactor, PWR simulators, radiochemistry laboratories, etc.).

Even now that the nuclear industry has reached full maturity, the Nuclear Engineering diploma is still unique in the French educational system, and affirms its mission: to train engineers who will have an in-depth, global vision of the science and the techniques applied in each phase of the life of nuclear installations from their design and construction to their operation and, finally, their dismantling.

The INSTN has committed itself to publishing all the course materials in a collection of books that will become valuable tools for students, and to publicise the contents of its courses in French and other European higher education institutions. These books are published by EDP Sciences, an expert in the promotion of scientific knowledge, and are also intended to be useful beyond the academic context as essential references for engineers and technicians in the industrial sector.

The European Nuclear Education Network (ENEN) fully supported INSTN, one of it founder members, in publishing this book. For ENEN this book constitutes the first of a series of textbooks intended for students and young professionals in Europe and worldwide, contributing to the creation of the European Educational Area.

Joseph Safieh

Nuclear Engineering Course Director

ENEN President 